\title{
Notes on procedure for the development of fuzzy rules in SCOP methodology
}

\author{
CHIDOZIE C NWOBI-OKOYE
}

Faculty of Engineering, Anambra State University (Chukwuemeka Odumegwu Ojukwu University), Uli, Nigeria e-mail: chidozien@yahoo.com; cc.nwobiokoye@coou.edu.ng

MS received 17 July 2018; revised 13 December 2018; accepted 21 December 2018; published online 4 February 2019

\begin{abstract}
The lack of statistical foundations among other shortcomings of existing methods of measuring efficiency necessitated the development of a new method called, Systems Coefficient of Performance Methodology (SCOPM). One key feature of SCOP methodology is the use of fuzzy logic to express complex efficiency measurement parameters into linguistic variables understandable by non experts and the general public. In this research note, the procedure for development of membership functions for the fuzzy logic aspect of SCOPM modeling was standardized and presented. A thorough analysis of fuzzy logic modeling which is at the heart of SCOPM was done. Real life examples and case studies are used to highlight the practical applications and utility of the methodology. The study gives a deep insight into the strengths of SCOP as an efficiency measurement method and its superiority over other efficiency measurement methods like, Data Envelopment Analysis (DEA), Stochastic Frontier Analysis (SFA), etc. Finally, a guide to practitioners on implementation of SCOPM as well as future research direction for academics and researchers is presented.
\end{abstract}

Keywords. Systems coefficient of performance methodology (SCOPM); fuzzy logic; membership functions; efficiency.

\section{Introduction}

Imagine a world where there are no metrics for measuring efficiency or evaluating performance. There would be severe pollution, environmental degradation, economic hardship, sickness and death. Such a world is better imagined than experienced. Nature has laid down very good examples of how to make processes and systems efficient which are carefully crafted in evolutionary procedures and algorithms found in nature. Measurement and improvement of efficiency is at the heart of systems engineering and operations management. The first step towards efficiency improvement is the development of appropriate metric for measuring it. Efficiency measurement has evolved for centuries. The earliest efficiency measurement methods involve the use of simple ratio indicators such as output per man hour, income per unit cost, power output per unit fuel consumption, etc [1]. In this method efficiency is determined by output divided by input [1-3]. This method is used for single input single output systems, processes or Decision Making Units (DMUs). The ratio indicators are autonomous metrics used for measuring the efficiency of a given DMU in isolation of other DMUs. In other words, ratio indicators are not relative efficiency measurement metric [1-3]. Since ratio indicators cannot handle cases where the DMU has multiple inputs and/or outputs, another method of efficiency measurement known as weighted average method (WAM) was developed [1]. In this method, the efficiency is given by the ratio of weighted sum of outputs divided by the weighted sum of inputs. A major weakness of this method is the difficulty in assigning appropriate weights to the inputs and outputs [1]. These methods stated above are known as non parametric methods of measuring efficiency.

Economists quite unlike engineers are often concerned with the performance and efficiency of several DMUs. But engineers are usually concerned with the performance and efficiency of a single DMU which normally is either a plant, machine or equipment. In order to measure the efficiency of several DMUs, an efficiency measurement method known as Stochastic Frontier Analysis (SFA) was developed [1, 4-7]. SFA is a parametric method of measuring efficiency and assumes that there is variability of inputs and outputs across the DMUs whose efficiencies are being measured. Based on this, the SFA methodology uses regression analysis to obtain the efficiency of the DMUs relative to the average performing DMU. Hence, SFA determines the performance of DMU's relative to the average performer(s) [5-7]. Major weaknesses of SFA include the fact that it does not take into consideration the variability of inputs and outputs within a particular DMU and also in situations where the DMUs have multiple inputs and outputs, SFA is somewhat difficult to use $[1-4,7]$. Two other parametric methods that are closely related to SFA 
are Thick Frontier Approach (TFA) and Distribution Free Approach (DFA), and these have weaknesses similar to SFA [1].

In order to overcome some of the deficiencies of SFA and its siblings, especially in handling cases of multiple inputs and outputs, and weighted average method, Charnes et al [8] introduced a non parametric efficiency measurement method called Data Envelopment Analysis (DEA). DEA was primarily developed to measure the efficiency of groups of DMUs with multiple inputs and outputs [9-15]. DEA measures the efficiency of a DMU relative to the best performer(s). DEA is related to the weighted average method but uses an optimization method called linear programming to assign weights to the inputs and outputs [1, 9-12]. A major weakness of DEA is that it lacks statistical foundations and does not take into consideration the variability of inputs and outputs in a DMU [1-3, 9-12]. Also, DEA is a relative measure and not an autonomous metric $[1,7,10,11]$. Another non parametric efficiency measurement method that is very closely related to DEA is called the Free Disposal Hall (FDH) [1].

As a consequent of efforts to further improve the accuracy of efficiency measurements, another parametric efficiency measurement method called System's Coefficient of Performance Methodology (SCOPM) was recently developed [2, 3, 16-19]. SCOPM measures efficiency by taking into consideration the fact that there is variability of inputs and outputs to a DMU [2, 3, 16-19]. SCOP also takes into consideration the possibility of output lagging the input in the determination of efficiency of a DMU. SCOPM uses transfer functions and fuzzy logic in the determination of the efficiency of a DMU. SCOPM is a completely different variant of another method of measuring performance using fuzzy logic developed by Gill and Singh [20] for measuring the coefficient of performance (efficiency) of refrigeration systems.

Gill and Singh [20] used parameters of the refrigeration system as fuzzy variables to predict its coefficient of performance. But SCOP methodology uses system transfer function parameters as fuzzy variables in order to predict the efficiency of systems, processes and DMUs. Apart from the work of Gill and Singh [20], there are several cases in the literature where fuzzy logic was used to predict performance. These cases include but not limited to Gill and Singh [21], Li et al [22], Beikkhakhian et al [23], Brusakova and Kosuhina [24], Barkana et al [25], Bray et al [26], Kumar and Vaidehi [27], Balasubramanian et al [28], Srinivasan and Raajarajan [29], etc. SCOP methodology differs from these because in the methodology transfer function parameters are the fuzzy variables.

The main purpose of this paper is to expatiate on the fuzzy logic modeling of SCOP methodology. The paper is organized in this manner. Following this introduction is a brief introduction to SCOP methodology, following the brief introduction of SCOPM is the detailed notes on the Fuzzy Modeling aspect of SCOPM, following this is the discussion of findings and finally the conclusions.

\section{Introduction to Systems Coefficient of Performance (SCOP) methodology}

The Systems Coefficient of Performance (SCOP) methodology, is a relatively method of measuring efficiency as stated in the introduction. To understand the concept of SCOP, it is pertinent to note that other efficiency measurement methods as was earlier stated do not take into consideration the general variability of input(s) and output(s) to a DMU, process/system. But an in-depth study of DMUs, systems and processes shows that input(s) to DMUs/systems/processes is stochastic and output(s) is stochastic [2, 3, 16-19]. Hence, there is a general variability of input(s) and output(s) to DMUs, processes or systems. This phenomenon is illustrated in figure 1 for single input single output (SISO) DMUs/systems/processes.

If, as have been observed, there is variability in input(s) and output(s) to systems, it implies that efficiency is stochastic. Also, sometimes the output may lag the input depending on the efficiency of the system or process. Thus, the conventional methods of measuring efficiency as stated above are technically deficient $[2,3]$. The consequence of the findings is that the correct way to measure efficiency is to find the best statistical modeling technique for relating the input(s) of processes to output(s). Of course the variability of input(s) and output(s) makes relating input(s) and output(s) complex. Since there are several statistical models of relating input(s) to output(s), Nwobi-Okoye and Igboanugo $[2,3]$ proposed that in order to better understand the complex relationship between the input and output to a process or system, an analytical technique known as transfer function modeling is the most appropriate. They proposed the use of discrete transfer function model applied to modeling systems and process performance as stated in Equation (1).

$$
Y_{t}=\delta^{-1}(B)^{r} \omega(B)^{s} X_{t-b}+N_{t}
$$

Here

$Y_{t}=$ process output at time $t, X_{t}=$ process input at time $t$, $\omega=$ difference equation variable for input

$\delta=$ difference equation variable for output, $\mathrm{b}=$ transfer function lag, $B=$ backshift operator, $N_{t}=$ noise term

Allowing for several inputs, $X_{1, t}, X_{2, t}, \ldots, X_{m, t}$ we have:

$$
\begin{aligned}
Y_{t}= & \delta^{-1}(B)^{r} \omega_{1}(B)^{s} X_{1, t-b}+\ldots+\delta^{-1}(B)^{r} \omega_{m}(B)^{s} X_{m, t-b} \\
& +N_{t}
\end{aligned}
$$

Nwobi-Okoye and Igboanugo [2, 3], Nwobi-Okoye et al [18] successfully proposed that transfer functions could be 


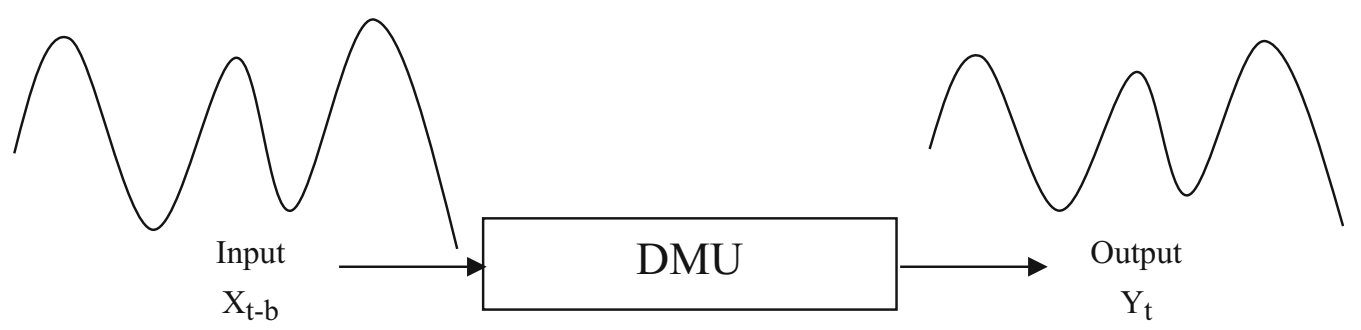

Figure 1. Schematic of the input-output relationship for a SISO DMU.

used as the predictor tool, with the variables $\delta, \omega, \mathrm{b}$ and $\mathrm{N}_{\mathrm{t}}$ in Equations (1) and (2) serving as maintenance status and operation's efficiency indicators, hence they went ahead and devised schemes to demonstrate this fact [2, 3, 16-19].

According to Nwobi-Okoye et al [18], for the models in Equations (1) and (2), the simplest case occurs when r, s and $\mathrm{N}_{\mathrm{t}}$ are zero and $\mathrm{b}$ is a constant. For other case scenarios, $\delta, \omega, b$ and $\mathrm{N}_{\mathrm{t}}$ are regarded as fuzzy numbers. Thus for the parameter, $\omega$, we can define a fuzzy set such that:

$$
\mu_{\mathrm{A}_{\mathrm{i}}}(\omega) \in[0,1]
$$

where $A_{i}$ denotes membership function $\mathrm{i}$ of $\omega$.

Since $\delta, \omega, \mathrm{b}$ and $\mathrm{N}_{\mathrm{t}}$ are fuzzy variables, they could be used as inputs to a fuzzy inference system using either the MAMDANI, SUGENO or any other suitable fuzzy inference model to generate an output, $\lambda$, which measures the efficiency or performance of the process or system.

The parameters $\delta, \omega, \mathrm{b}$ and $\mathrm{N}_{\mathrm{t}}$ are regarded as minor coefficients of performance $\left(\mathrm{SCOP}_{\text {minor }}\right)$, while the parameter, $\lambda$, is regarded as the major coefficient of performance $\left(\mathrm{SCOP}_{\text {major }}\right)$. The minor and major coefficients of performance (COP) are the most statistically robust measures of efficiency and performance of a system or process [2, 3, 16-19].

For multiple outputs, we have intermediate major Systems Coefficients of Performance $\left(\right.$ ISCOP $\left._{\text {major }}\right)$ for each output. The final major Systems Coefficients of Performance $\left(\mathrm{FSCOP}_{\text {major }}\right)$ is obtained by fuzzifying the intermediate major Systems Coefficients of Performance and subsequently feeding the fuzzy variables into fuzzy inference system to obtain FSCOP major $_{\text {. }}$

The implication of the rule of Nwobi-Okoye et al [18] is that any transfer function parameter can be transformed into fuzzy variables and once transformed into fuzzy variables would always measure process/system efficiency effectively.

As an efficiency measurement method, SCOP methodology has several advantages over other methods some of which were stated in the introduction. In addition to the advantages, SCOP equally has some weaknesses. One of the strengths of SCOPM previously stated is that efficiency calculations take into consideration the fact that there is a variability of inputs and outputs to a DMU, hence efficiency values are highly guaranteed not to be susceptible to false positives and false negatives which is prevalent in other methods. Also, efficiency values take into consideration the possibility of lag of output to input. Although parametric methods are statistically sound, SCOPM is based on statistically superior transfer function modeling and hence statistically better than other methods [2, 3]. Quite unlike other parametric methods, SCOPM can easily measure the efficiency of DMUs with multiple outputs.

In continuation, the flexibility in setting the membership functions, fuzzy rules, and performance index in SCOP methodology means that efficiency values, quite unlike in SFA and other parametric methods, are not subject to problem of endogeniety bias. i.e., situations where the inputs or resources are endogenous variables. Also, SCOPM can be used to evaluate the performance of a single DMU as a unit without taking into consideration other DMUs. Hence, SCOPM is an autonomous or absolute metric. Furthermore, SCOP methodology can be used for both macro and micro level performance evaluation, hence making it a flexible tool $[2,3,17]$. Finally, the extensive data requirement of SCOP means that statistically robust efficiency values are derived directly from the data. SCOPM quite unlike DEA and FDH can easily model part of process inefficiencies that are due to noise and measurement errors.

Despite the numerous advantages of SCOP methodology over other efficiency measurement methods, it is not without some weaknesses. For instance, error in setting out the fuzzy logic rules in SCOP methodology could lead to wrong efficiency values. Also, SCOP methodology involves much more complex calculations than other methods of measuring efficiency.

\section{Procedure of transforming transfer function parameters to fuzzy variables}

\subsection{Multi input systems with desirable inputs}

Assume that for a multi input single output system the following model was obtained:

$$
Y_{1 t}=\mu_{y 1}+\omega_{01} x_{1 t}+\omega_{02} x_{2 t}
$$


Here $\omega_{01}=1, \omega_{02}=2, Y_{1 t}=$ Number of product 1 produced by machine 1 and machine 2. $x_{1 t} \equiv$ machine 1 , $x_{2 t} \equiv$ machine 2 .

Here, it is implied that machine 2 contributes to efficient operations twice more than machine 1. I.e. machine 2 is twice as fast as machine 1 in the production of product 1 .

Hence

$$
Y_{1 t}=\mu_{y 1}+1 x_{1 t}+2 x_{2 t}
$$

In setting the upper and lower limits of $\omega_{01}$ and $\omega_{02}$ for the fuzzy analysis, we have to assume the values such that:

$$
\begin{aligned}
& \omega_{01}=[0.5,1.5] \\
& \omega_{02}=[1.5,2.5]
\end{aligned}
$$

In other words, we must make sure that the sum of the upper and lower limits of the Systems Coefficients of Performance (SCOP) are the same as assumed above. i.e., sum $1=2.5+0.5=3.0$ and sum $2=1.5+1.5=3.0$.

This must be done before developing the membership functions and setting the fuzzy rules.

Assume $\omega_{01}=\mathrm{n}$ and $\omega_{02}=\mathrm{d}$.

Assuming the upper limit of $\mathrm{d}$ belongs to the membership function of $\mathrm{d}$ named High $\left(\mathrm{H}_{\mathrm{d}}\right)$ and the lower limit belongs to the membership function named Low $\left(\mathrm{L}_{\mathrm{d}}\right)$ and in a similar vein, upper limit of $n$ belongs to the membership function of $n$ named High $\left(\mathrm{H}_{\mathrm{n}}\right)$ and the lower limit belongs to the membership function named Low $\left(\mathrm{L}_{n}\right)$, it follows from above that:

$$
\mathrm{H}_{\mathrm{d}}+\mathrm{L}_{\mathrm{n}}=\mathrm{H}_{\mathrm{n}}+\mathrm{L}_{\mathrm{d}}
$$

Hence if $\mathrm{H}_{\mathrm{d}}=2.5, \mathrm{~L}_{\mathrm{n}}=0.5$ and $\mathrm{H}_{\mathrm{n}}=1.5$

Then

$$
\mathrm{L}_{\mathrm{d}}=\mathrm{H}_{\mathrm{d}}+\mathrm{L}_{\mathrm{n}}-\mathrm{H}_{\mathrm{n}}
$$

$$
\begin{aligned}
& \mathrm{L}_{\mathrm{d}}=1.5 \\
& \mathrm{H}_{\mathrm{d}}+\mathrm{H}_{\mathrm{n}}=4 ; \mathrm{H}_{\mathrm{d}}+\mathrm{L}_{\mathrm{n}}=3 ; \mathrm{H}_{\mathrm{n}}+\mathrm{L}_{\mathrm{d}}=3 ; \mathrm{L}_{\mathrm{d}}+\mathrm{L}_{\mathrm{n}}=2
\end{aligned}
$$

Assuming the output membership functions are three and consists of three linguistic variables Poor, Good and Excellent, and assuming the variables 2, 3 and 4 corresponds to Poor, Good and Excellent, respectively, the following fuzzy rules apply:

If $\mathrm{d}$ is high and $\mathrm{n}$ is high then Performance is Excellent If $\mathrm{d}$ is high and $\mathrm{n}$ is low, then Performance is Good If $\mathrm{d}$ is low and $\mathrm{n}$ is high then, Performance is Good If $\mathrm{d}$ is low and $\mathrm{n}$ is low then, Performance is Poor

The implication of rules 2 and 3 above is that for an autonomous value of output, $\mu_{y 1}$, if there is a unit increase in $x_{1}$ and $x_{2}$, the output, $Y_{t}$, is increased by 3 units [3].

Assuming that we have three minor Systems Coefficients of Performance named a, b, c and the upper and lower limits of $a$ and $b$ have been set as stated above, then

$$
\mathrm{H}_{\mathrm{a}}=6, \quad \mathrm{~L}_{\mathrm{a}}=2, \quad \mathrm{H}_{\mathrm{b}}=5 \text { and } \mathrm{L}_{\mathrm{b}}=1
$$

We set the upper and lower limits of $\mathrm{c}$ in two ways:

i. Set the upper and lower limits relative to a.

ii. Set the upper and lower limits relative to $b$.

3.1a Setting the upper and lower limits relative to a: Assume $\mathrm{H}_{\mathrm{c}}=4$,

$$
\begin{aligned}
& \mathrm{H}_{\mathrm{a}}+\mathrm{L}_{\mathrm{c}}=\mathrm{H}_{\mathrm{c}}+\mathrm{L}_{\mathrm{a}} \\
& \mathrm{L}_{\mathrm{c}}=\mathrm{H}_{\mathrm{c}}+\mathrm{L}_{\mathrm{a}}-\mathrm{H}_{\mathrm{a}}
\end{aligned}
$$

$\mathrm{L}_{\mathrm{c}}=0$

Therefore:

$$
\mathrm{H}_{\mathrm{b}}+\mathrm{L}_{\mathrm{a}}+\mathrm{H}_{\mathrm{c}}=\mathrm{H}_{\mathrm{a}}+\mathrm{H}_{\mathrm{b}}+\mathrm{L}_{\mathrm{c}}=11
$$

Assuming 11 corresponds to the linguistic variable of the performance membership function named Good, it follows that in the fuzzy logic language the following rules apply:

If $\mathrm{b}$ is high and $\mathrm{c}$ is high and $\mathrm{a}$ is low, then Performance is Good

If $\mathrm{a}$ is high and $\mathrm{b}$ is high and $\mathrm{c}$ is low, then Performance is Good.

\section{1.b Setting the upper and lower limits relative to} b: Assume $\mathrm{H}_{\mathrm{c}}=0.45$,

$$
\begin{aligned}
& \mathrm{H}_{\mathrm{b}}+\mathrm{L}_{\mathrm{c}}=\mathrm{H}_{\mathrm{c}}+\mathrm{L}_{\mathrm{b}} \\
& \mathrm{L}_{\mathrm{c}}=\mathrm{H}_{\mathrm{c}}+\mathrm{L}_{\mathrm{b}}-\mathrm{H}_{\mathrm{b}}
\end{aligned}
$$

$\mathrm{L}_{\mathrm{c}}=-3.55$

It follows that:

$$
\mathrm{H}_{\mathrm{b}}+\mathrm{L}_{\mathrm{a}}+\mathrm{H}_{\mathrm{c}}=\mathrm{H}_{\mathrm{a}}+\mathrm{H}_{\mathrm{b}}+\mathrm{L}_{\mathrm{c}}=7.45
$$

Assuming 7.45 corresponds to the linguistic variable of the performance membership function named Very Good, it follows that in fuzzy logic language the following rules apply:

If $b$ is high and $c$ is high and $a$ is low, then Performance is Very Good

If $\mathrm{a}$ is high and $\mathrm{b}$ is high and $\mathrm{c}$ is low, then Performance is Very Good

A practical case study of a multi input DMU is a power plant. Consider a power plant where the output is daily energy generated (MWh) and the inputs are daily fuel consumption (MMSCF/D) and daily operating expenditure (OPEX). The transfer functions for two years are as shown in table 1 .

The upper and lower limits of minor SCOPs $\left(\omega_{01}\right)$ were set to 1.2 and 0 , respectively. Also, the upper and lower limits of minor SCOP $\left(\omega_{02}\right)$ were set to 0.02 and -1.18 , respectively in order to adhere to the rules mentioned above. 
Table 1. Transfer functions and minor SCOP for the crushing plants.

\begin{tabular}{cccc}
\hline & & \multicolumn{2}{c}{ Minor SCOP } \\
\cline { 3 - 4 } Description & Transfer function & $\omega_{01}$ & $\omega_{02}$ \\
\hline 2014 & $Y_{t}=\mu_{y}+1.11 x_{t}+0.0078 x_{t}$ & 1.11 & 0.0078 \\
2015 & $Y_{t}=\mu_{y}+0.89 x_{t-1}+0.0117 x_{t}$ & 0.89 & 0.0117 \\
\hline
\end{tabular}

Subsequently, five membership functions were created for the minor SCOPs $\omega_{01}$ and $\omega_{02}$ as shown in figures 2 and 3. The membership function consists of five linguistic variables namely: $\mathrm{VH}$ for very high value, $\mathrm{H}$ for high value, A for average value, $L$ for low value and VL for very low value. Also output membership functions consisting of five linguistic variables namely: Outstanding (O), Excellent (E), Good $(\mathrm{G})$, Fair $(\mathrm{F})$ and Poor $(\mathrm{P})$ were developed for the fuzzy analysis. The output membership functions are as shown in figure 4.

Twenty five rules were developed for a fuzzy inference system whose output was the efficiency of the power plant. The output of the fuzzy inference system is shown in table 2.

As shown in table 2, the year 2014 with a major SCOP of 0.9574 which corresponds to the linguistic variable 'outstanding' was more efficient than the year 2015 with a major SCOP of 0.8674 which corresponds to the linguistic variable 'Excellent'.

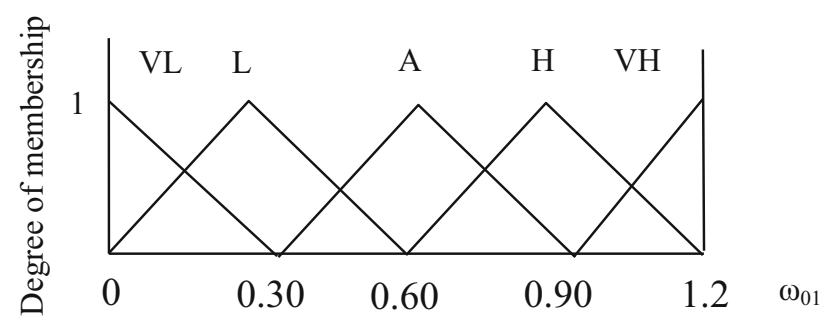

Figure 2. The membership functions of $\omega_{01}$.

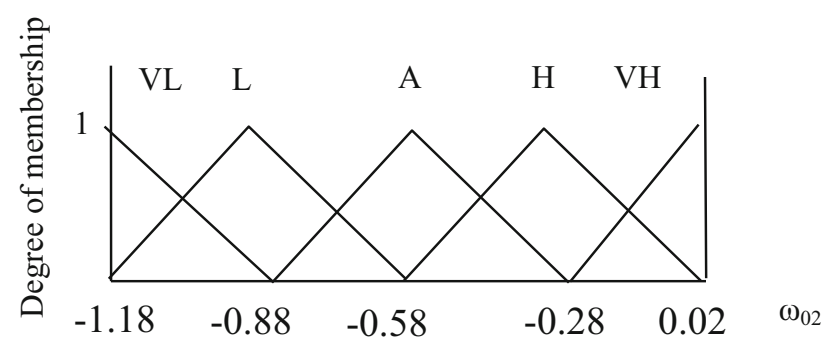

Figure 3. The membership functions of $\omega_{02}$.

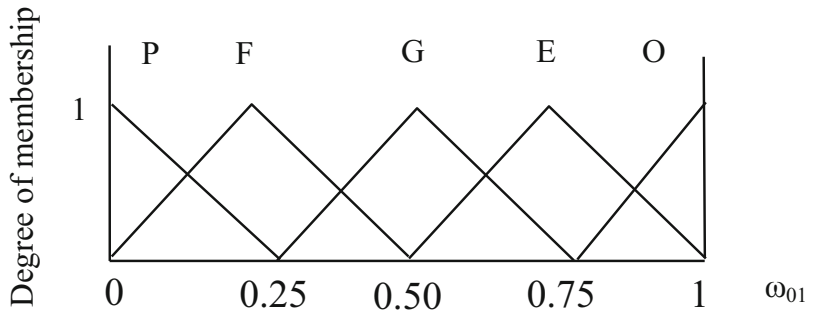

Figure 4. The membership functions for the performance of the power plant.

Table 2. Transfer functions and major SCOP for the power plant.

\begin{tabular}{|c|c|c|c|c|}
\hline \multirow[b]{2}{*}{ Description } & \multicolumn{2}{|c|}{ Minor SCOP } & \multirow{2}{*}{$\begin{array}{c}\text { Major SCOP } \\
\text { (Efficiency) } \\
\lambda\end{array}$} & \multirow{2}{*}{$\begin{array}{c}\text { Linguistic } \\
\text { variable }\end{array}$} \\
\hline & $\omega_{01}$ & $\omega_{02}$ & & \\
\hline 2014 & 1.11 & 0.0078 & 0.9574 & Outstanding \\
\hline 2015 & 0.89 & 0.0117 & 0.8674 & Excellent \\
\hline
\end{tabular}

\subsection{Modeling DMUs with undesirable inputs}

There are some situations where one or more inputs are undesirable. For instance in some processes, additives are added if the quality of raw materials is poor in order to boost the quality of the product/output [16, 18, 19]. Assuming input two (n) in section 3.1 above is undesirable, in order to develop the rules, we set up a virtual minor SCOP for $\mathrm{n}$ and $\mathrm{d}$ thus:

$$
\mathrm{d}_{v}=[1,2] ; \quad \mathrm{n}_{v}=[1,2]
$$

The linguistic variables of the membership function is reversed as shown in table 3 such that the upper limit of $\mathrm{n}$ belongs to the membership function of $\mathrm{n}$ named Low $\left(\mathrm{L}_{\mathrm{n}}\right)$ and the lower limit belongs to the membership function named High $\left(\mathrm{H}_{\mathrm{n}}\right)$. Hence the following rules apply:

If $\mathrm{d}$ is high and $\mathrm{n}$ is high, then Performance is Good If $\mathrm{d}$ is high and $\mathrm{n}$ is low, then Performance is Excellent If $\mathrm{d}$ is low and $\mathrm{n}$ is high, then Performance is Poor If $d$ is low and $n$ is low, then Performance is Good

For a practical case study, consider the performance of two palm kernel crushing plants in South East Nigeria. Each DMU/process is a single input single output process/DMU where the input is the batch quantity of palm kernel that enters the plant daily, while the output is the quantity of vegetable oil obtained daily from each batch. The transfer functions and minor SCOP of the two plants for the year 2016 is as shown in table 4.

In this model, $\omega_{0}$ is a desirable input because the higher the value the better the conversion of palm kernels to vegetable oil, but the lag (b) is regarded as undesirable 
Table 3. Linguistic variables reversal for undesirable input.

\begin{tabular}{cccc}
\hline $\mathrm{d}_{\mathrm{v}}$ & Linguistic Variable & $\mathrm{n}_{\mathrm{v}}$ & Linguistic Variable \\
\hline 2 & High & 1 & High \\
1 & Low & 2 & Low \\
\hline
\end{tabular}

Table 4. Transfer functions and minor SCOP for the crushing plants.

\begin{tabular}{lccc}
\hline & & \multicolumn{2}{c}{ Minor SCOP } \\
\cline { 3 - 4 } Description & Transfer function & $\omega_{0}$ & $\mathrm{~b}$ \\
\hline Plant A & $Y_{t}=\mu_{y}+0.43 x_{t}$ & 0.43 & 0 \\
Plant B & $Y_{t}=\mu_{y}+0.54 x_{t-1}$ & 0.54 & 1 \\
\hline
\end{tabular}

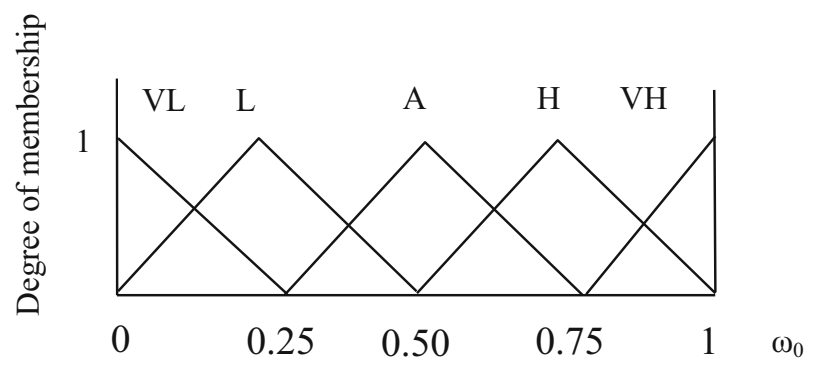

Figure 5. The membership functions for $\omega_{0}$.

because the bigger the value the poorer the performance of the plant. The membership function for $\omega_{0}$ is shown in figure 5. In figure 5, the linguistic variable denoted by $\mathrm{VH}$ is very high desirability, $\mathrm{H}$ is high desirability, $\mathrm{A}$ is average desirability, L is low desirability while VL is very low desirability.

On the assumption that the maximum lag (b) is 5 days and the minimum lag is 0 , the lag (b) undergoes a transformation to bring it into the same unit with $\omega_{0}$ by dividing each lag variable by 5 . Hence the virtual lag $b_{v}$ is given by:

$$
b_{v}=\frac{b}{5}
$$

Following this transformation, the maximum virtual lag is 1 and the minimum is 0 .

The membership function for $\mathrm{b}$ is as shown in figure 6 . As shown in Figure 6, the linguistic variable denoted by $\mathrm{VH}$ is very high desirability, $\mathrm{H}$ is high desirability, $\mathrm{A}$ is average desirability, $\mathrm{L}$ is low desirability while $\mathrm{VL}$ is very low desirability. As figure 6 shows, the linguistic variables of the membership function of $b_{v}$ have been reversed when compared to that of $\omega_{0}$ shown in figure 5 .

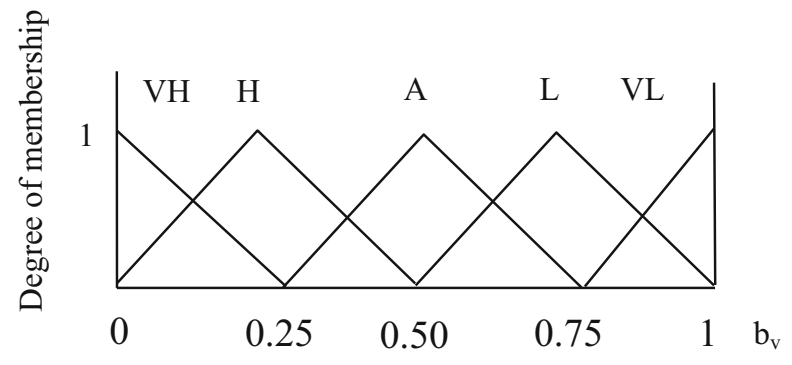

Figure 6. The membership functions for $b_{v}$.

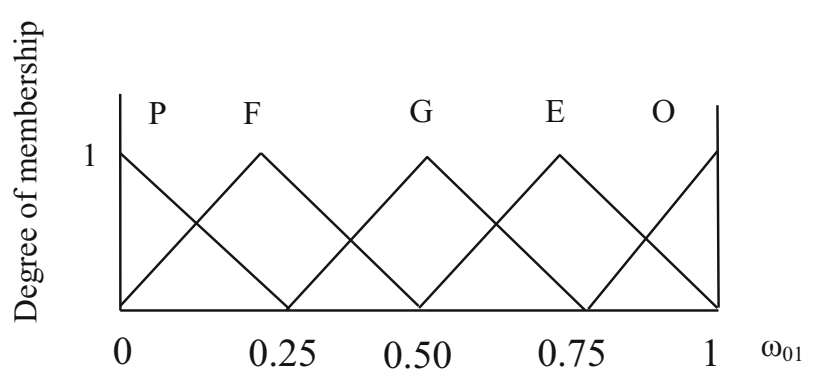

Figure 7. The membership functions for the performance of the palm kernel crushing plants.

The membership function for the output shown in figure 7 has five linguistic variables namely: Outstanding $(\mathrm{O})$, Excellent (E), Good (G), Fair (F) and Poor (P).

From the input and output membership functions, 25 fuzzy rules were developed for the performance assessment of the plants and some of the rules are as stated below:

If $\omega$ is high and $b$ is very high then Performance is Outstanding

If $\omega$ is Average and b is very high, then Performance is Excellent

If $\omega$ is very low and $b$ is very high, then Performance is Good

If $\omega$ is very low and $b$ is very low, then Performance is Poor

Table 5 shows the Major SCOP for the two palm kernel crushing plants. As shown in table 5, plant A with higher major SCOP $(\lambda)$ was more efficient than plant $B$.

Table 5. Transfer functions and major SCOP for the crushing plants.

\begin{tabular}{|c|c|c|c|c|}
\hline \multirow[b]{2}{*}{ Description } & \multicolumn{2}{|c|}{$\begin{array}{l}\text { Minor } \\
\text { SCOP }\end{array}$} & \multirow{2}{*}{$\begin{array}{c}\text { Major SCOP } \\
\text { (Efficiency) } \\
\lambda\end{array}$} & \multirow{2}{*}{$\begin{array}{c}\text { Linguistic } \\
\text { variable }\end{array}$} \\
\hline & $\omega_{0}$ & $\mathrm{~b}$ & & \\
\hline Plant A & 0.43 & 0 & 0.7064 & Excellent \\
\hline Plant B & 0.54 & 1 & 0.6150 & Good \\
\hline
\end{tabular}


Table 6. Fuzzification of noise.

\begin{tabular}{lc}
\hline Noise $(\%)$ & Linguistic variable \\
\hline 10 & Very high \\
7.5 & High \\
5 & Slightly high \\
2.5 & Low \\
0 & Very low \\
\hline
\end{tabular}

\subsection{Fuzzifying noise}

Noise, which could be due to environment, weather, natural disaster, vandalization, etc, affects efficiency significantly. To obtain SCOP in noisy DMUs/processes/systems requires the fuzzification of the noise model [16]. To fuzzify noise in SCOP methodology, the upper and lower limit of the average percentage of output signal due to noise has to be set. For example, assuming maximum of $10 \%$ of the output and minimum of $0 \%$ could be due to noise, we could fuzzify the noise signals with the following linguistic variables shown in table 6.

As a case study let us consider the performance of a metal can manufacturing plant in Lagos, Nigeria. The plant uses sheet metals to produce metal cans for packaging milk. The input consists of daily sheet metal usage in $\mathrm{Kg}$ while the output is the daily quantity of tin cans produced in $\mathrm{Kg}$. The transfer functions for a two year period of operations of the plant in the years 2015 and 2016 are as shown in table 7. In 2016, the plant output was affected by noise with a moving average (MA) ARIMA model as shown in table 7 .

The membership functions for $\omega_{0}$ are shown in figure 8 . The membership function consists of five linguistic variables namely: $\mathrm{VH}$ for very high desirability, $\mathrm{H}$ for high desirability, A for average desirability, L for low desirability and VL for very low desirability.

For the noise it is assumed that the maximum and minimum percentage of the output due to noise should be $+0.01 \%$ and $-0.01 \%$, respectively. Positive values of the percentage noise means that the noise enhanced the output while negative values means that the noise reduced the output. Hence to obtain the average percentage of output due to noise $\left(N_{\mathrm{p}}\right)$ involves the following procedure:

Recall that the transfer function $v(B)$ is related to the forecast output signals $\left(\widehat{Y}_{t}\right)$ by:

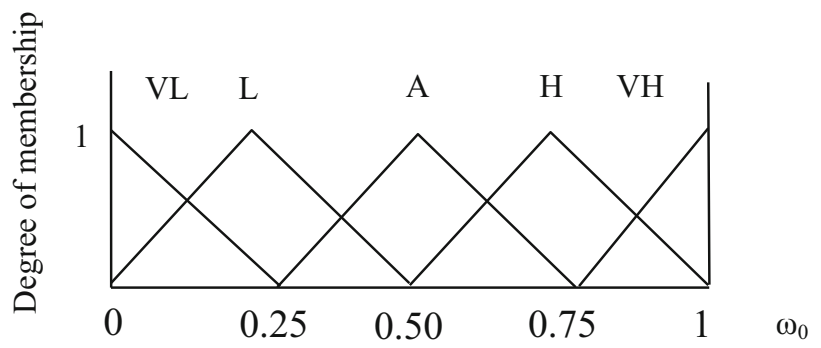

Figure 8. The membership functions for $\omega_{0}$ for the tin can plant.

$$
\widehat{Y}_{t}=v(B) X_{t-b}+N_{t}
$$

The output signal without the noise is given by:

$$
\hat{Y}_{1 t}=v(B) X_{t-b}
$$

The average predicted output without noise $(\bar{Q})$ is given by:

$$
\bar{Q}=\frac{\sum_{t=1}^{n} \hat{Y}_{1 t}}{n}
$$

Where $\mathrm{n}$ is the number of time periods under consideration.

The average noise effect $(\overline{Q N})$ on the process is given by:

$$
\overline{Q N}=\frac{\sum_{t=1}^{n} N_{t}}{n}
$$

But

$$
N_{p}=\frac{\overline{Q N}}{\bar{Q}} \times 100
$$

Equation (11) is very similar to signal to noise ratio which measures how noise affects the signals of a process.

Using the calculations above, the average percentage of output due to noise of the tin can plant obtained was + 0.000526 in 2016.

In order to fuzzify the noise, the percentage noise is transformed to a virtual minor SCOP $N_{\text {tv }}$ by the following transformation.

$$
N_{t v}=\frac{N_{p}-(-0.01)}{0.02}
$$

Fuzzifying the noise signals $\mathrm{N}_{\mathrm{tv}}$ we obtain the membership function shown in figure 9. As figure 9 shows, the linguistic

Table 7. Transfer functions and minor SCOP for the tin can plant.

\begin{tabular}{lccc}
\hline & & \multicolumn{2}{c}{ Minor SCOP } \\
\cline { 3 - 4 } Year & Transfer function & $\omega_{0}$ & $\mathrm{~N}_{\mathrm{t}}$ \\
\hline 2015 & $Y_{t}=\mu_{y}+0.9812 x_{t}$ & 0.9812 & 0 \\
2016 & $Y_{t}=\mu_{y}+0.9934 x_{t}+0.7723 e_{t-1}+0.15 e_{t-2}$ & 0.9934 & +0.000526 \\
\hline
\end{tabular}




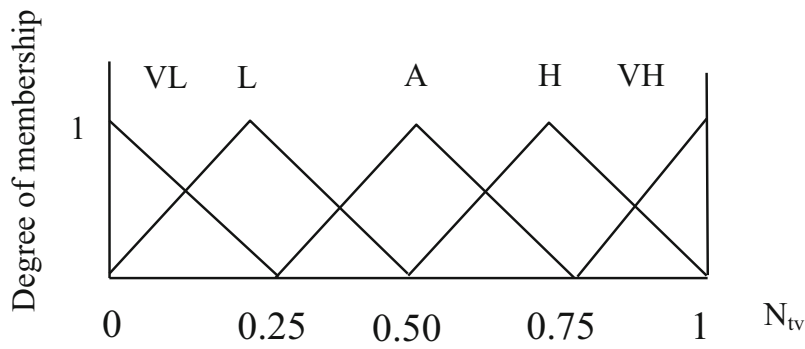

Figure 9. The membership functions for noise $\left(\mathrm{N}_{\mathrm{tv}}\right)$.

Table 8. Major SCOP for the tin can plant.

\begin{tabular}{ccccc}
\hline & \multicolumn{2}{c}{ Minor SCOP } & & \\
\cline { 2 - 4 } Year & $\omega_{0}$ & $\mathrm{~N}_{\mathrm{t}}$ & $\begin{array}{c}\text { Major SCOP } \\
(\lambda)\end{array}$ & Linguistic variable \\
\hline 2015 & 0.9812 & 0 & 0.5128 & Good \\
2016 & 0.9934 & +0.000526 & 0.7657 & Excellent \\
\hline
\end{tabular}

variable denoted by $\mathrm{VH}$ is very high desirability, $\mathrm{H}$ is high desirability, A is average desirability, $\mathrm{L}$ is low desirability while VL is very low desirability.

The output membership functions consist of five linguistic variables which are Outstanding $(\mathrm{O})$, Excellent $(\mathrm{E})$, Good $(\mathrm{G})$, Fair $(\mathrm{F})$ and Poor $(\mathrm{P})$. Combining the inputs through a fuzzy inference system the major $\operatorname{SCOP}(\lambda)$ was obtained as shown in table 8 . As shown in table 8 , year 2016 with a major SCOP $(\lambda)$ of 0.7657 was more efficient than the year 2015 with a major SCOP $(\lambda)$ of 0.5128 .

\subsection{Modeling multi output systems or DMUs}

In situations where the processes studied are multi output processes, DMUs or systems, the fuzzy analysis is handled in this manner:

Let us assume the following model for two output systems.

$$
\begin{aligned}
& Y_{1 t}=\mu_{y 1}+1 x_{1 t}+2 x_{2 t} \\
& Y_{2 t}=\mu_{y 2}+2 x_{1 t}+4 x_{2 t}
\end{aligned}
$$

$Y_{1 t}=$ Number of product 1 produced by machine 1 and machine 2.

$Y_{2 t}=$ Number of product 2 produced by machine 1 and machine 2 .

It is assumed that product 2 is faster to produce than product 1 .

From our previous analysis in section 3.1, let us assume that for product 1 the following holds:
Table 9. Linguistic variables for $\lambda_{1}$ and $\lambda_{2}$.

\begin{tabular}{lcc}
\hline$\lambda_{1}$ & $\lambda_{2}$ & Linguistic variable \\
\hline 4 & 8 & Excellent \\
3 & 6 & Good \\
2 & 4 & Fair \\
\hline & & \\
& $\omega_{01}=[0.5,1.5] ;$ & $\omega_{02}=[1.5,2.5]$
\end{tabular}

And for product 2 the following holds:

$$
\omega_{01}=[1.0,3.0] ; \quad \omega_{02}=[3.0,5.0]
$$

The upper and lower limits of the intermediate major SCOP (ISCOP $\left.{ }_{\text {major }}\right) \lambda_{1}$ and $\lambda_{2}$ obtained via output 1 (product 1) and output 2 (product 2), respectively is as stated below:

$$
\lambda_{1}=[2,4] ; \quad \lambda_{2}=[4,8]
$$

If we assume the linguistic variables shown in table 9 for $\lambda_{1}$ and $\lambda_{2}$, it implies that $\lambda_{1}$ carries more weight than $\lambda_{2}$ since with a value of 4 it is already regarded as excellent while $\lambda_{2}$ requires a value of 8 to be excellent. It is expected because product 2 is faster to produce than product 1 .

To obtain the final major SCOP (FSCOP $\left.{ }_{\text {major }}\right)\left(\lambda_{\mathrm{f}}\right)$ as stated in section 2, we first have to set the rules. To set the rules, since $\lambda_{1} \equiv \lambda_{2}$, we set up a virtual SCOP thus:

$$
\lambda_{v 1}=[1,3] ; \quad \lambda_{v 2}=[1,3]
$$

Assuming that $\lambda_{\mathrm{f}}$ has five membership functions namely: Outstanding, Excellent, Good, Fair, Poor then with reference to $\lambda_{\mathrm{v}}$ some of the following rules will apply:

If $\lambda_{1}$ is Excellent and $\lambda_{2}$ is Excellent, then $\lambda_{\mathrm{f}}$ is Outstanding

If $\lambda_{1}$ is Excellent and $\lambda_{2}$ is Good, then $\lambda_{\mathrm{f}}$ is Excellent

If $\lambda_{1}$ is Excellent and $\lambda_{2}$ is Fair, then $\lambda_{\mathrm{f}}$ is Good

If $\lambda_{1}$ is Good and $\lambda_{2}$ is Fair, then $\lambda_{\mathrm{f}}$ is Fair

Having developed these rules using the virtual minor SCOP, we revert back to the membership functions developed with the actual minor SCOP as shown in figure 10 to find $\lambda_{\mathrm{f}}$.

To obtain the final major SCOP (FSCOP $\left.{ }_{\text {major }}\right)\left(\lambda_{\mathrm{f}}\right)$, we have to determine the upper and lower limits of the output membership functions of $\lambda_{\mathrm{f}}$ which are given by:

$$
\lambda_{\text {fupper }}=\lambda_{\text {lupper }}+\lambda_{\text {2upper }}=12
$$

The lower limit of $\lambda_{\mathrm{f}}$ is given by:

$$
\lambda_{\text {fLower }}=\lambda_{1 \text { Lower }}+\lambda_{2 \text { Lower }}=6
$$

Hence,

$$
\lambda_{f}=[6,12]
$$

It is noteworthy that the upper and lower limits of the output membership functions of $\lambda_{\mathrm{f}}$ are not sacrosanct. For 


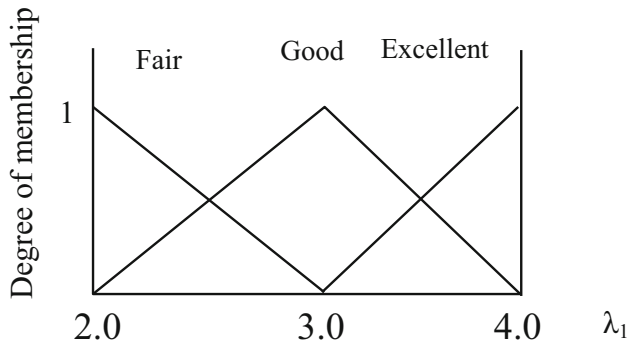

(a)

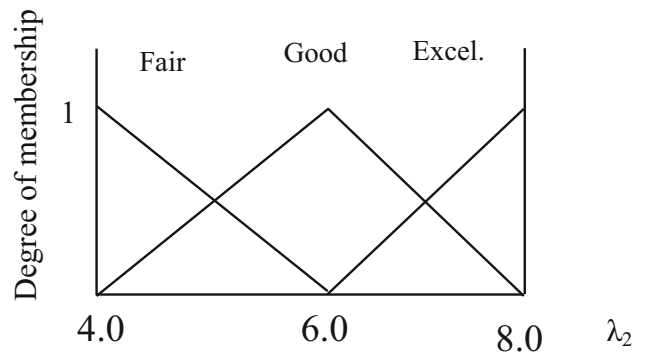

(b)

Figure 10. (a) Membership functions for $\lambda_{1}$. (b) Membership functions for $\lambda_{2}$.

Table 10. Transfer functions for the refinery.

\begin{tabular}{lccccc}
\hline & \multicolumn{4}{c}{ Transfer Function } \\
\cline { 2 - 5 } Year & LPG & Petrol & Kerosene & Diesel & Fuel Oil \\
\hline 2009 & $Y_{t}=\mu_{y}+0.0396 x_{t}$ & $Y_{t}=\mu_{y}+0.2451 x_{t}$ & $Y_{t}=\mu_{y}+0.1509 x_{t}$ & $Y_{t}=\mu_{y}+0.2409 x_{t}$ & $Y_{t}=\mu_{y}+0.2848 x_{t}$ \\
2010 & $Y_{t}=\mu_{y}+0.0431 x_{t}$ & $Y_{t}=\mu_{y}+0.2531 x_{t}$ & $Y_{t}=\mu_{y}+0.1503 x_{t}$ & $Y_{t}=\mu_{y}+0.2692 x_{t}$ & $Y_{t}=\mu_{y}+0.2256 x_{t}$ \\
\hline
\end{tabular}

Table 11. Intermediate major SCOP and final major SCOP for the refinery.

\begin{tabular}{cccccccr}
\hline & \multicolumn{4}{c}{ Intermediate major SCOP (ISCOP $\left.{ }_{\text {major }}\right)$} & \multicolumn{2}{c}{ Final major SCOP (FSCOPmajor) } \\
\cline { 2 - 6 } Year & LPG $\left(\boldsymbol{\lambda}_{\mathbf{1}}\right)$ & Petrol $\left(\boldsymbol{\lambda}_{\mathbf{2}}\right)$ & Kerosene $\left(\boldsymbol{\lambda}_{\mathbf{3}}\right)$ & Diesel $\left(\boldsymbol{\lambda}_{\mathbf{4}}\right)$ & Fuel Oil $\left(\boldsymbol{\lambda}_{\mathbf{5}}\right)$ & 0.5166 & Linguistic variable \\
\hline 2009 & 0.0396 & 0.2451 & 0.1509 & 0.2409 & 0.2848 & 0.5089 & Good \\
2010 & 0.0431 & 0.2531 & 0.1503 & 0.2692 & 0.2256 & Good \\
\hline
\end{tabular}

example one can choose the upper and lower limits upper of $\lambda_{\mathrm{f}}$ such that:

$$
\lambda_{f}=[0.25,1]
$$

It is very important to note that in setting the upper and lower limits of intermediate major SCOP (ISCOP ${ }_{\text {major }}$ ), the upper and lower limits must be chosen with reference to the ISCOP $_{\text {major }}$ with the lowest coefficients, such that the upper and lower limits must be multiples of the upper and lower limits of the ISCOP ${ }_{\text {major }}$ with the lowest coefficients. Hence if $\operatorname{ISCOP}_{\text {major }}\left(\lambda_{1}\right)$ has the lowest coefficients for the upper and lower limits then:

$$
\begin{gathered}
\lambda_{\text {2upper }}=\mathrm{k} \lambda_{\text {lupper }} ; \quad \lambda_{3 \text { upper }}=L \lambda_{\text {lupper }} ; \\
\lambda_{\text {4upper }}=\mathrm{m} \lambda_{\text {lupper }} ; \quad \lambda_{5 \text { upper }}=\mathrm{n} \lambda_{\text {lupper }} \\
\lambda_{\text {2lower }}=\mathrm{k} \lambda_{\text {llower }} ; \quad \lambda_{3 \text { lower }}=\mathrm{L} \lambda_{1 \text { lower }} ; \\
\lambda_{\text {4lower }}=\mathrm{m} \lambda_{\text {llower }} ; \quad \lambda_{\text {5lower }}=\mathrm{n} \lambda_{\text {llower }}
\end{gathered}
$$

A petroleum refinery is an example of a multi output process. Consider the transfer functions from a petroleum refinery in Warri, Nigeria as shown in table 10. The input to the refinery is crude oil while the outputs are five namely: petrol, kerosene, diesel, LPG and fuel oil.

Table 11 shows the Intermediate major SCOP and final major SCOP for the refinery. Three membership functions were created for each intermediate major SCOP $\left(\right.$ ISCOP $\left._{\text {major }}\right)$. The linguistic variables of the membership functions were: High, Average and Low as shown in figure 11 for $\lambda_{2}$ and $\lambda_{3}$.

The output membership function shown in figure 12 consists of five linguistic variables namely: Outstanding (O), Excellent (E), Good (G), Fair (F) and Poor (P).

From the membership functions, 243 rules were created and from the fuzzy rules the final major SCOP $\left(\mathrm{FSCOP}_{\text {major }}\right)\left(\lambda_{\mathrm{f}}\right)$ shown in table 11 were obtained.

As shown in table 11, the year 2009 with final major SCOP (FSCOP ${ }_{\text {major }}$ ) of 0.5166 was more efficient than the year 2010 with a final major SCOP (FSCOP major ) of 0.5089.

3.4a Modeling multi output systems with undesirable output: In cases where the output is undesirable, for example assuming that product 2 is undesirable (like emissions in 


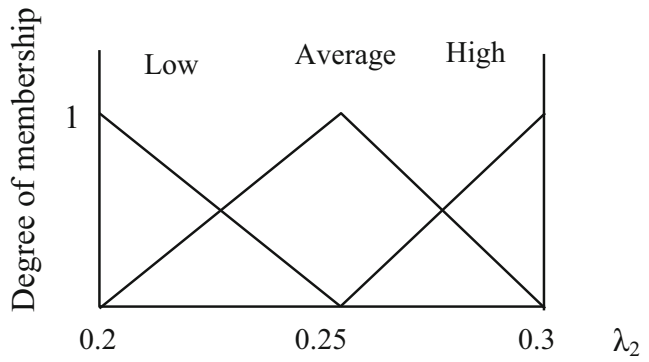

(a)

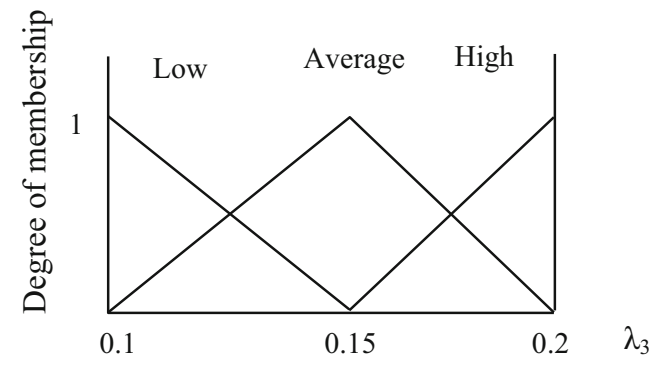

(b)

Figure 11. (a) Membership functions for $\lambda_{2}$ (Refinery). (b) Membership functions for $\lambda_{3}$ (Refinery).

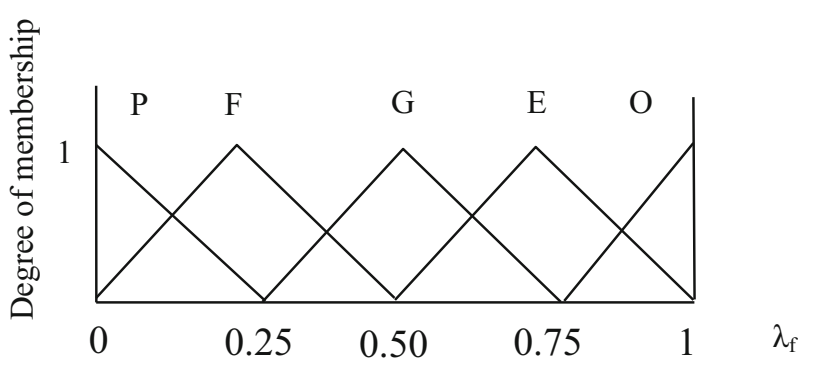

Figure 12. The membership functions for the performance of the refinery.

Table 12. Linguistic variables reversal for undesirable output.

\begin{tabular}{lccc}
\hline$\lambda_{1}$ & Linguistic variable & $\lambda_{2}$ & Linguistic variable \\
\hline 4 & Excellent & 8 & Fair \\
3 & Good & 6 & Good \\
2 & Fair & 4 & Excellent \\
\hline
\end{tabular}

Table 13. Transfer functions for the power plant.

\begin{tabular}{lll}
\hline & \multicolumn{2}{c}{ Transfer function } \\
\cline { 2 - 3 } Year & Energy generated & Emissions \\
\hline 2016 & $Y_{t}=\mu_{y}+69.11 x_{t}$ & $Y_{t}=\mu_{y}+32.93 x_{t}$ \\
2017 & $Y_{t}=\mu_{y}+89.16 x_{t}$ & $Y_{t}=\mu_{y}+41.82 x_{t}$ \\
\hline
\end{tabular}

power plants) the minor SCOP is set up such that the linguistic variables of $\lambda_{2}$ are reversed as shown in table 12 .

An exemplification of a multi output DMU with undesirable output is the power plant where the emissions constitute the undesirable output. Consider this power plant with transfer functions shown in table 13. The outputs consist of emissions in tons and energy generated in $\mathrm{MWh}$, while the input is the gas consumption in MMSCF/D.

Table 14 shows the obtained Intermediate major SCOP of the power plant. Five membership functions were
Table 14. Intermediate major SCOP and final major SCOP for the power plant.

\begin{tabular}{|c|c|c|c|c|}
\hline \multirow[b]{2}{*}{ Year } & \multicolumn{2}{|c|}{$\begin{array}{l}\text { Intermediate major } \\
\text { SCOP } \text { ISCOP }_{\text {major }} \text { ) }\end{array}$} & \multirow{2}{*}{$\begin{array}{c}\text { Final major } \\
\text { SCOP } \\
\left(\text { FSCOP }_{\text {major }}\right)\end{array}$} & \multirow[b]{2}{*}{$\begin{array}{c}\text { Linguistic } \\
\text { variable }\end{array}$} \\
\hline & $\begin{array}{c}\text { Generated } \\
\left(\lambda_{1}\right)\end{array}$ & $\begin{array}{c}\text { Emissions } \\
\left(\boldsymbol{\lambda}_{2}\right)\end{array}$ & & \\
\hline 2016 & 69.11 & 32.93 & 0.6157 & 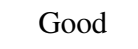 \\
\hline 2017 & 89.16 & 41.82 & 0.6651 & Excellent \\
\hline
\end{tabular}

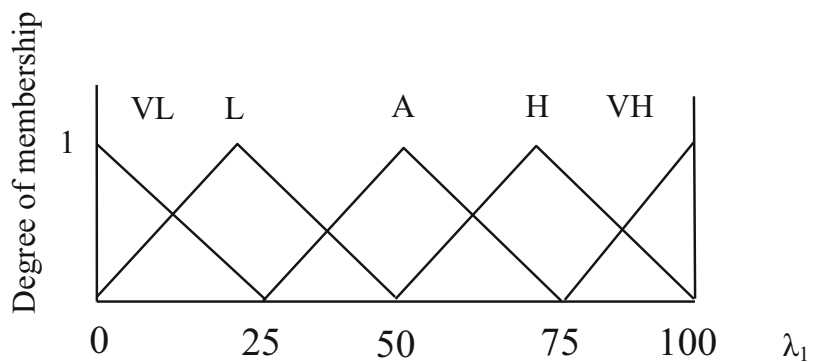

Figure 13. The membership functions for $\lambda_{1}$ of the power plant.

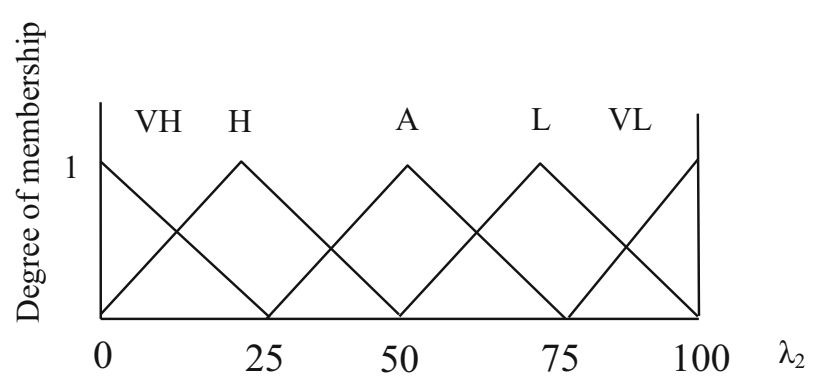

Figure 14. The membership functions for $\lambda_{2}$ of the power plant.

created for each intermediate major SCOP (ISCOP ${ }_{\text {major }}$ ) as shown in figures 13 and 14 . The linguistic variables of the membership function denoted by $\mathrm{VH}$ is very high 


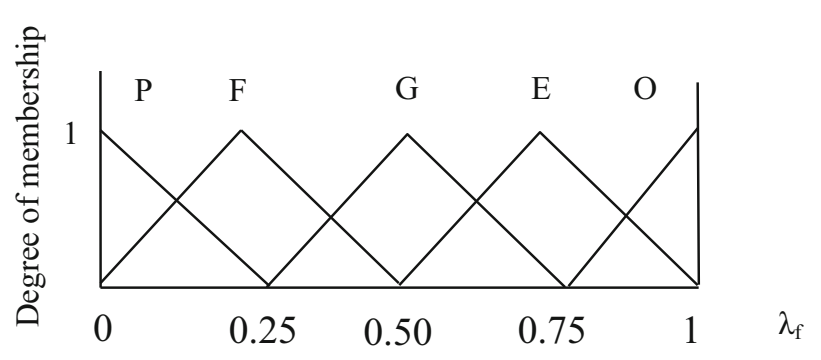

Figure 15. The membership functions for $\lambda_{\mathrm{f}}$ of the power plant.

desirability, $\mathrm{H}$ is high desirability, $\mathrm{A}$ is average desirability, $\mathrm{L}$ is low desirability while VL is very low desirability as shown in figures 13 and 14.

As shown in figure 14, based on the rule above the linguistic variables of the membership functions for $\lambda_{2}$ have been reversed.

The output membership function developed for the fuzzy modeling is as shown in figure 15 .

The output membership function shown in figure 15 consists of five linguistic variables namely: Outstanding $(\mathrm{O})$, Excellent (E), Good (G), Fair (F) and Poor (P).

Following the procedures for the development of the membership functions and fuzzy rules, the final major SCOPs of the power plant were obtained in table 14. As shown in table 14, the year 2017 had higher final major SCOP than the year 2016. Hence operations in 2017 were more efficient than in 2016.

\section{Discussion}

The cases studied here have a maximum of five fuzzy variables. Cases of six or more variables do occur and their analyses follow the same procedure. Once the lower and upper limits have been set and their membership functions identified. Intermediate membership functions can always be set by dividing the membership functions evenly across the range. For fuzzy modeling, triangular membership function performs better than others and is therefore the preferred shape of membership functions for SCOPM evaluations.

Analysis in this work shows that precise computation of efficiency is a complex and rigorous task. The rigour employed in determination of efficiency through transfer function modeling and fuzzy logic in SCOP methodology ensures that false positives or false negatives, prevalent in other methods, are all but eliminated. If efficiency measurements in a DMU are false positives, operations managers would assume that the DMU is doing well while in actual fact it is not. By the time the managers may discover the true state of affairs it might be too late. On the other hand, false negatives might lead to unnecessary cost cutting measures, increase in expenditure on maintenance, etc. Of great significance in SCOPM is the elegant way the methodology deals with noise in processes which affect output. SCOPM quite unlike DEA is able to isolate and model noise factors that affect efficiency. This is wonderful because with this methodology managers would be able to know part of the inefficiency that could be attributed to noise. For example, in power system DMUs noise factors like bad weather, such as heavy winter, heavy rains, etc usually cause faults on power lines. In addition natural disasters like earthquake, flood, Tsunami, hurricanes, tornadoes, lightning, etc could cause damage to power generation, transmission and distribution systems. Also pests such as squirrels, raccoons, birds, rabbits, etc often cause faults on power lines. Operational performance of power systems, as well as other systems can also be affected by environmental variables like $\mathrm{PH}$, salinity, etc.

\section{Conclusions}

As an efficiency measurement method, the key advantage of SCOP over Stochastic Frontier Analysis (SFA), Data Envelopment Analysis (DEA) and other efficiency measurement methods are that SCOP methodology takes into consideration the variability of input (s) and output (s) to a process or system and secondly SCOP equally takes into consideration the possibility of output lagging the inputs to model the efficiency of complex systems and processes. SCOP methodology through the use of fuzzy logic converts complex efficiency measurement variables into understandable linguistic variables for the purpose of reporting to regulatory bodies or government agencies, organizations, general public, interested parties and non experts. It is therefore necessary to educate future users of SCOP methodology, the details of the procedure for fuzzy modeling in SCOP methodology in order to obtain consistent results as has been thoroughly done in this research note.

The major disadvantage of SCOP methodology is the computational rigour involved in the calculation of efficiency, although the current existence of cheap and powerful computer hardware and software tools have almost made this seeming weakness irrelevant. Another limitation of SCOP methodology is the extensive data requirement, and some small scale industrial organizations may find it difficult to keep such data. Implementing SCOP methodology may require change in data gathering methods, purchase of new computer software and hardware, training of personnel, etc. Hence, for practitioners implementing SCOP methodology in industrial organizations requires either a pilot or parallel conversion. For big industrial organizations with several DMUs, pilot conversion is advocated. For small industrial organizations with a single DMU, parallel conversion where the new system runs side by side with the old system until the old system retires, is advocated. For academics and future researchers on SCOP methodology, it is advocated that serious research efforts be directed towards the development of sophisticated special 
purpose software completely devoted to SCOP methodology. This is very essential as DEA and SFA have specialized software for their application.

\section{References}

[1] Vincová K 2005 Using DEA models to measure efficiency. Biatec. 13(8): 24-28

[2] Nwobi-Okoye C C and Igboanugo A C 2012 Performance evaluation of hydropower generation system using transfer function modelling. Int. J. Electr. Power Energy Syst. 43(1): 245-254

[3] Nwobi-Okoye C C and Igboanugo A C 2015 Performance appraisal of gas based electricity power generation system using transfer function modelling. Ain Shams Eng. J. 6 (2015): 541-551

[4] Jacobs R 2001 Alternative methods to examine hospital efficiency: data envelopment analysis and stochastic frontier analysis. Health Care Manag. Sci. 4(2): 103-115

[5] Martín J C, Román C and Voltes-Dorta A 2009 A stochastic frontier analysis to estimate the relative efficiency of Spanish airports. J. Prod. Analys. 31(3): 163-176

[6] Cullinane K and Song D W 2006 Estimating the relative efficiency of European container ports: a stochastic frontier analysis. Res. Trans. Econ. 16: 85-115

[7] Cooper W W, Seiford L M and Zhu J 2004 Data envelopment analysis. In: Handbook on data envelopment analysis, Boston, MA: Springer, pp. 1-39

[8] Charnes A, Cooper W W and Rhodes E 1978 Measuring the efficiency of decision making units. Eur. J. Oper. Res. 2(6): 429-444

[9] Cook W D and Seiford L M 2009 Data envelopment analysis (DEA)-Thirty years on. Eur. J. Oper. Res. 192(1): 1-17

[10] Mardani A, Zavadskas E K, Streimikiene D, Jusoh A and Khoshnoudi M 2016 A comprehensive review of data envelopment analysis (DEA) approach in energy efficiency. Renew. Sust. Energy Rev. 70:1298-1322

[11] Sueyoshi T, Yuan Y and Goto M 2016 A Literature study for DEA applied to energy and environment. Energy Econ. 62:104-124

[12] Liu C H, Lin S J and Lewis C 2010 Evaluation of thermal power plant operational performance in Taiwan by data envelopment analysis. Energy Policy 38(2): 1049-1058

[13] Rezaee M J, Moini A and Makui A 2012 Operational and nonoperational performance evaluation of thermal power plants in Iran: a game theory approach. Energy 38(1): 96-103

[14] Song C, Li M, Zhang F, He Y L and Tao W Q 2015 A data envelopment analysis for energy efficiency of coal-fired power units in China. Energy Conver. Manag. 102: 121-130

[15] Sözen A, Alp İ and Kilinc C 2012 Efficiency assessment of the hydro-power plants in Turkey by using Data Envelopment Analysis. Renew. Energy 46: 192-202

[16] Nwobi-Okoye C C 2017 Neuro-fuzzy model for evaluating the performance of processes using transfer function.
Sadhana 42(12): 2055-2065. https://doi.org/10.1007/s12046017-0744-3

[17] Nwobi-Okoye C C 2018 Transfer function based performance assessment of power distribution facilities: a case study of distribution transformers. J. Electr. Syst. Inf. Technol. 5(3):977-993. http://dx.doi.org/10.1016/j.jesit.2016.12. 001.

[18] Nwobi-Okoye C C, Okiy S and Igboanugo A C 2016 Performance evaluation of multi-input-single-output (MISO) production process using transfer function and fuzzy logic: case study of a brewery. Ain Shams Eng. J. 7: 1001-1010. http://dx.doi.org/10.1016/j.asej.2015.07.008

[19] Nwobi-Okoye C C and Okiy S 2016 Performance assessment of multi-input-single-output (MISO) production process using transfer function and fuzzy logic: case study of soap production. Cog. Eng. 3(1): 1257082. http://dx.doi.org/10. 1080/23311916.2016.1257082

[20] Gill J and Singh J 2017 Performance analysis of vapor compression refrigeration system using an adaptive neurofuzzy inference system. Int. J. Refrig. 82: 436-446

[21] Gill J and Singh J 2018 An applicability of ANFIS approach for depicting energetic performance of VCRS using mixture of R134a and LPG as refrigerant. Int. J. Refrig. 85: 353-375

[22] Li W, Liang W, Zhang L and Tang Q 2015 Performance assessment system of health, safety and environment based on experts' weights and fuzzy comprehensive evaluation. $J$. Loss Prev. Process Ind. 35: 95-103

[23] Beikkhakhian Y, Javanmardi M, Karbasian $M$ and Khayambashi B 2015 The application of ISM model in evaluating agile suppliers selection criteria and ranking suppliers using fuzzy TOPSIS-AHP methods. Expert Syst. Appl. 42(15-16): 6224-6236

[24] Brusakova I A and Kosuhina M A 2015 The fuzzy logic method for innovation performance measurement. In: Soft Computing and Measurements (SCM), 2015 XVIII International Conference on (pp. 291-293). IEEE.

[25] Barkana B D, Saricicek I and Yildirim B 2017 Performance analysis of descriptive statistical features in retinal vessel segmentation via fuzzy logic, ANN, SVM, and classifier fusion. Knowl. Bas. Syst. 118: 165-176

[26] Bray S, Caggiani L and Ottomanelli M 2015 Measuring transport systems efficiency under uncertainty by fuzzy sets theory based Data Envelopment Analysis: theoretical and practical comparison with traditional DEA model. Trans. Res. Proc. 5: 186-200

[27] Kumar P A and Vaidehi V 2017 A transfer learning framework for traffic video using neuro-fuzzy approach. Sādhanā. 42(9):1431-1442

[28] Balasubramanian R, Sankaran R and Palani S 2017 Simulation and performance evaluation of shunt hybrid power filter using fuzzy logic based non-linear control for power quality improvement. Sādhanā 42(9):1443-1452

[29] Srinivasan S P and Raajarajan L 2017 Wear rate and surface coating optimization of coconut coir-based polymer using fuzzy logic. Sādhanā 42(3):281-290 